\title{
Regulation of air exchange in urban areas to improve their environment
}

\author{
Botir Giyasov ${ }^{1, *}$, and Irina Giyasova ${ }^{2}$ \\ ${ }^{1}$ Moscow State University of Civil Engineering, 26, Yaroslavskoe sh., 129337, Moscow, Russia \\ ${ }^{2}$ Tambov State Technical University, 106, Sovetskaya ul., Tambov, 392000, Russia
}

\begin{abstract}
Environmental issues in cities are some of the causes of reduction in the average life expectancy of people, increase in the incidence and mortality of the population. According to scientists, health of the urban population is $20 \%$ dependent on the state of the natural environment. Urban residents are more likely to suffer from cardiovascular diseases, respiratory diseases, and blood circulation problems. In the course of urban development, people have a significant negative impact on the biosphere, changing it and being a part of it, they experience the consequences of these changes on themselves. This situation is complicated by the lack of a unified approach among civil engineers, architects, hygienists and environmentalists in the matters of organizing a residential environment. The article focuses on identification and analysis of sources of pollution affecting the air basin of modern cities. A comparative analysis of the transport and construction industries and their role in urban pollution is carried out. Using the example of the city of Moscow, calculations have been made and the indicators of the wind speed variation along the height of the building have been determined, depending on the type of terrain. These data allow assessing the formation of air exchange in urban areas and can be used to solve the problems of improving the urban environment.
\end{abstract}

\section{Introduction}

Modern urban environment is the environment surrounding a person at any city facility: in the open areas of residential areas, transport highways, inside public transport or buildings for various purposes. As a result of urbanization, the inevitable contradictions between humanity and nature, between anthropogenic activity and natural processes contribute to the emergence of a new habitat. With the development of education and culture, with the emergence of new ways of spending free time people have put forwards new requirements to architectural and functional solutions of residential areas and new approaches to design of urban dwellings [1]. Due to this, the territories of modern cities are rapidly developing, changing the established climatic and environmental conditions.

The urban environment undergoes constant changes fueled by the development of living conditions. The way of life and the spatial environment are subject to constant changes aimed at saving time in all spheres of life. This calls for the creation of new types and forms of

* Corresponding author: dandyr@mail.ru 
housing, the structure of the city and transport networks, which seriously complicates the environmental condition in urban areas.

A modern urban area is a set of complex architectural forms, which significantly affect the environment of the area. In this regard, both industrial and residential areas with densely constructed buildings can be considered environmentally unfavorable. High-rise civil buildings, being an integral part of a modern city, significantly affect the environmental situation of the city's air basin [2,3]. The air basin of a city with dense residential buildings is constantly exposed to the impact of various sources of pollution due to the activities of citizens, as well as due to the active use of motor vehicles. Table 1 lists the main sources of air pollution, which are subdivided into natural and man-made. Natural sources of pollution are of a natural origin, which does not depend on a human being. Man-made sources of pollution are caused by anthropogenic factors, resulting from human activity.

Table 1. Sources of air pollution.

\begin{tabular}{|c|c|}
\hline Natural & Manmade \\
\hline dust storms & industry \\
\hline volcanism & transport \\
\hline forest fires & thermal power engineering \\
\hline weathering & heating of houses \\
\hline decomposition of living organisms & agriculture \\
\hline
\end{tabular}

As can be seen from Fig. 1, environmental pollution is mainly due to consumption of fuel and energy resources by various sectors of the economy. [4].

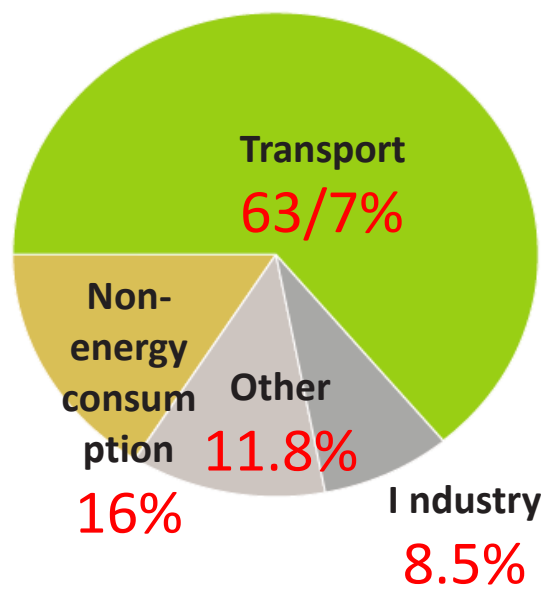

Fig. 1. Consumption of oil products by industry.

In modern cities, the main consumer of fuel and energy resources is transport, the use of which increases the amount of emissions of harmful substances into the environment.

Thus, modern urban areas with a developed transport infrastructure are one of the causes of unstable environmental condition. Obviously, urban transport can be considered as one of the important sources of pollution. 
On the other hand, if we consider energy consumption as a whole, all civil buildings consume more energy than the whole industry with its factories, industrial and metallurgical plants and energy, which is spent on transport with all its cars, trains and ships (Fig. 2) [5] .

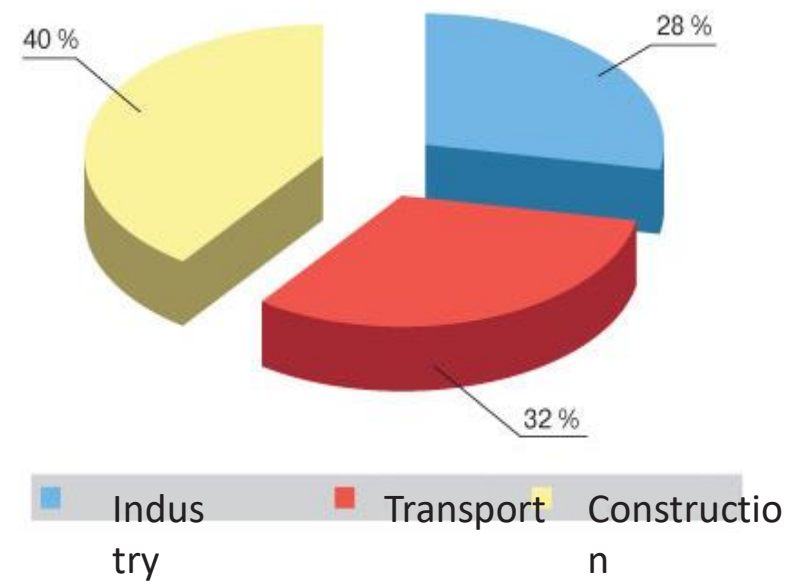

Fig. 2. Consumption of energy by industry.

Such intensive energy consumption, accompanied by constant emissions, also increases the level of pollution in the urban environment. Therefore, it should be noted that an increase in the density of urban areas, due to the increase in the number of civil buildings, negatively affects the environmental situation.

Obviously, the energy consumption of buildings depends on the characteristics of natural and climatic factors, the shape of the building and the orientation. All the buildings that form the city, being geometric figures and volumetric polygons, react differently to natural and climatic factors. The heat resistance and, consequently, the energy consumption of buildings depend directly on their shapes and volumes. The task of lowering the energy consumption of civil buildings by increasing their heat resistance should be considered as one of the priority tasks of improving the urban environment.

In this connection, a dense urban area and the growth of urban transport are the main factors that adversely influence the environmental situation of modern cities.

The process of urban development contributes to a change in the spatial and planning structure of the territories, causing a rapid increase in the number of roads and the density of road traffic. As a result of increasing density of buildings, natural aeration of the territory is changed. This causes the formation of extensive and stable zones with the most unfavorable atmospheric air parameters in the air basin of a modern city. These zones include areas with a radial-circular arrangement of streets and enclosed courtyards of cities. A significant increase in the air pollution level is fueled by air stagnation in residential areas, which is due to surface temperature inversion and no-wind conditions, when wind speeds are from 0 to 1 $\mathrm{m} / \mathrm{s}$. Thus, the issue of the formation of microclimatic and environmental conditions and their impact on the buildings of modern cities is insufficiently studied.

The natural wind regime is affected in the yard space of a modern city due to dense highrise buildings and promotes concentration of pollutants due to lack of required ventilation. One of the solutions to the problem of the urban airspace is to provide the necessary air exchange in courtyard spaces.

The air exchange of closed yard spaces, where natural aeration is poor, largely depends on the wind speed increasing in the facades of buildings. Modern cities are characterized by high-rise buildings. At the facades of a high-rise building, the wind speed usually increases along their height, and in the summer convective currents increase in the facades irradiated 
by the sun. As a result, powerful turbulent flows appear at the facades, depending on the shape of the building, the terrain, surrounding buildings and other factors.

\section{Materials and methods}

Various models are used to estimate the change in wind speed in altitude: the Ekman spiral, the logarithmic law, the power law $[7,8]$. These models are used to measure the wind speed $V$ at height $h$ if the wind speed $V_{0}$ is known at height $h_{0}$.

The power law of the wind speed variation with respect to height has the form $[7,8]$ :

$$
V_{h}=V_{0}\left(h / h_{0}\right)^{a} \quad \mathrm{~m} / \mathrm{s}
$$

where $V_{h}$ is wind speed, $\mathrm{m} / \mathrm{s}$, at height h, m;

$V_{0}$ is wind speed, $\mathrm{m} / \mathrm{s}$ measured at height $h_{0}, \mathrm{~m}$ (wind speed is measured at a height of 10$15 \mathrm{~m}$, therefore $\left.h_{0}=10-15 \mathrm{~m}\right)$;

$\alpha$ is an exponent that depends on the type of terrain and is found experimentally; it is recommended to assume for centers of big cities $\alpha=0,33$, for suburban areas $\alpha=0,22$, for open terrain $\alpha=0,14$ [8].

The values of wind speed at a height of $10 \mathrm{~m}$ are assumed to be equal to the values from tables 3.1 and 4.1 [12], for the city of Moscow for the warm and cold periods of the year.

Based on the calculation results, the graph was constructed (Fig. 3).

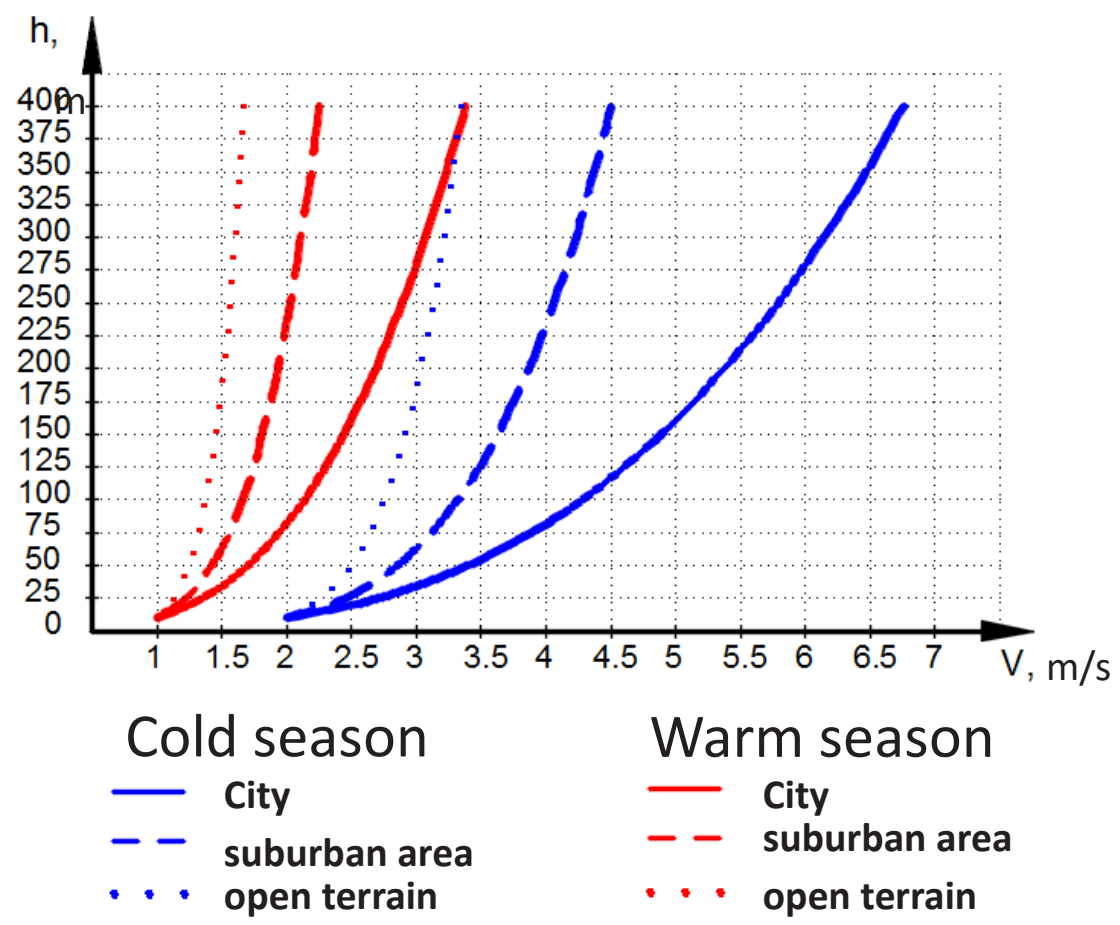

Fig. 3. Change in wind speed along the height of the building. 
At the same time, often known is the wind speed measured at the meteorological station, which is usually located in the open area. In conditions of dense urban area, the wind speed at the same height will be lower. The wind speed $\mathrm{V}$ at height $\mathrm{h}$, depending on the terrain type in the power law model, is calculated by the formula $[7,8]$ :

$$
V_{h}=V_{0}\left(\delta / h_{0}\right)^{\alpha_{0}}(h / \delta)^{\alpha}, \mathrm{m} / \mathrm{s}
$$

where $V_{h}$ is wind speed, $\mathrm{m} / \mathrm{s}$, at height h, m, in a terrain, the type of which is characterized by the exponent $\alpha$ and thickness of the boundary layer $\delta$;

$V_{0}$ is wind speed, $\mathrm{m} / \mathrm{s}$, measured at height $h_{0}, \mathrm{~m}$, in a terrain, the type of which is characterized by the exponent $\alpha_{0}$ and thickness of the boundary layer $\delta_{0}$;

$\alpha$ is the exponent, depending on the type of terrain and found experimentally; $\delta$

is thickness of the boundary layer, $\mathrm{m}$, for the type of terrain under consideration; in [8] the following values are recommended $-\alpha$ and $\delta$ :

- for large city centers $\alpha=0,33, \delta=460 \mathrm{~m}$;

- for suburban conditions (in this case a suburb is understood as a terrain in which a lowrise building or forest parks are located within a radius of $2000 \mathrm{~m}) \alpha=0,22,{ }^{\delta}=370 \mathrm{~m}$;

- for open terrain $\alpha=0,14,{ }^{\delta}=270 \mathrm{~m}$.

$\alpha_{0}, \delta_{0}$ are exponent and thickness of the boundary layer for the terrain on which the wind speed V0 is meausred; as a rule, wind speeds are measured at meteorological stations located in the open area, at a height of 10-15 m, and in this case $h_{o}=10-15 \mathrm{~m}, \alpha_{0}=0,14, \delta_{0}=270$ m.

Based on the results of the calculation, a graph of the wind speed dependence on the height of the building is constructed, taking into account the terrain type ( Fig.4) 


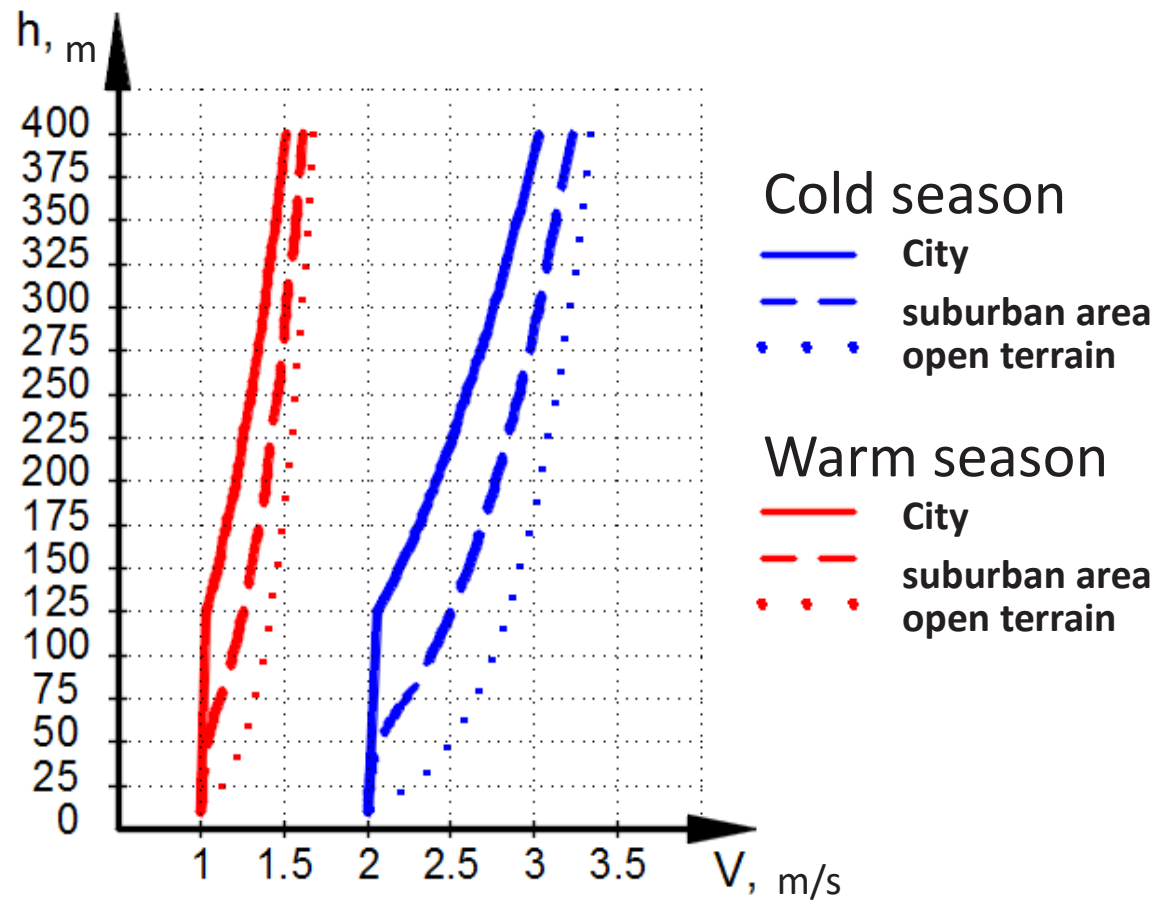

Fig. 4. Change in wind speed along the height of the building.

Thus, the air exchange of courtyard spaces depends on the type of terrain, the nature of the building and its height.

\section{Conclusions}

1. To ensure optimal air exchange in urban areas, it is necessary to apply rational planning and spatial solutions.

2. In order to reduce the influence of pollution sources on the urban environment, it is necessary to create streets without intersections, prohibit through traffic in residential areas. It is advisable to create zones in the residential part of the city that are free of traffic.

3. When planning urban areas and designing buildings, it is necessary to take into account the features of the geometric shapes and conditions for placing high-rise buildings on the formation of the heat-wind regime of the terrain.

4. In these studies, the environmental effects of urbanized areas have been assessed. The analysis of factors causing pollution in the city's air basin has been made, and the sources of pollution that have the greatest impact on the urban environment have been identified.

5. The presented calculations have made it possible to reveal the factors influencing the formation of the wind regime of modern urban areas and assess their role in the ecology of the urban environment.

\section{References}

1. B.I. Giyasov, Zhurnal Vestnik MGSU 4, 17-21 (2012)

2. B. Giyasov, I. Giyasova, E3S Web of Conferences 33, 01045 (2018) 
3. V.N. Pryahin, A.L. Bol'sherotov, N.E. Ryazanova, Zhurnal Vestnik RUDN, seriya Ekologiya i bezopasnost' zhiznedeyatel'nosti 3, 72-76 (2009)

4. A. Bashmakov, Energosberezhenie 1, 62-67 (2010)

5. B.M. Shojhet, Ehnergosberezhenie 7, 62-66 (2007)

6. B.I. Kochurov, I.V. Ivashkina, Problemy regional'noj ekologii 4, 24-32 (2010)

7. Je. Simiu, R. Skanlan, Vozdejstvie vetra na zdanija i sooruzhenija (Strojizdat, Moscow, 1984)

8. ASHRAE Handbook. Fundamentals (Si Edition, 1997)

9. Ju.A. Tabunshhikov, AVOK 8 (2004) https://www.abok.ru/for_spec/articles php?nid=2662

10. O.D. Samarin, Zhilishhnoe stroitel'stvo 1, 32-33 (2013)

11. Ju.A.Tabunshhikov, M.M. Brodach, N.V. Shilkin, Jenergojeffektivnye zdanija (AVOKPRESS, Moscow, 2003)

12. Russian Standard SP 131.13330.2012 